\title{
Forearm orientation in Hadrosauridae (Dinosauria: Ornithopoda) and implications for museum mounts
}

\author{
Phil Senter
}

\begin{abstract}
Skeletons of hadrosaurids ("duck-billed dinosaurs") are usually mounted with palms facing caudally (posteriorly). To achieve this, the radius is articulated with the medial (ulnar) condyle of the humerus instead of the lateral (radial) condyle, which would be unique among vertebrates if it were correct. However, articulated specimens reveal that in hadrosaurids the radius articulates with the lateral condyle of the humerus, as in other vertebrates, and the palms face caudomedially, though more medially than caudally. Active pronation is prevented by the shapes of the radial and ulnar shafts and by the lack of rolling articulations between radius and ulna. This makes the caudomedial orientation of the palm permanent. This finding contradicts many museum mounts but agrees with trackway evidence.
\end{abstract}

Phil Senter. Department of Biological Sciences, Fayetteville State University, 1200 Murchison Road, Fayetteville, North Carolina 28301, U.S.A, psenter@uncfsu.edu

KEY WORDS: Hadrosauridae; Ornithopoda; Ornithischia; Dinosauria; forelimb; museum; skeletal mounts; fossil preparation

\section{INTRODUCTION}

In most tetrapods the distal end of the humerus exhibits two condyles: a lateral (radial) condyle that articulates with the head of the radius and a medial (ulnar) condyle that articulates with the proximal end of the ulna. Because the thumb is aligned with the radius and the fifth finger is aligned with the ulna, the orientation of the forearm determines the orientation of the hand. A plethora of studies have involved examination of forelimb articulations to determine antebrachial and manual orientation in saurischian dinosaurs (Sereno, 1993; Gishlick, 2001; Carpenter, 2002; Bonnan, 2003;
Senter and Robins, 2005; Senter, 2006; Senter and Parrish, 2006; Bonnan and Senter, 2007) and in ornithischian dinosaurs of the clades Thyreophora (Senter, 2010, 2011) and Ceratopsia (Senter 2007; Fujiwara 2009), but the forelimbs of ornithischian dinosaurs of the family Hadrosauridae have not received such attention. For this study I examined antebrachial and manual orientation in Hadrosauridae. Hadrosauridae is a clade of herbivorous dinosaurs from the Late Cretaceous of North and South America, Europe, Asia, and Antarctica. The group is characterized by the presence of a complex dental battery and by modification of the snout 


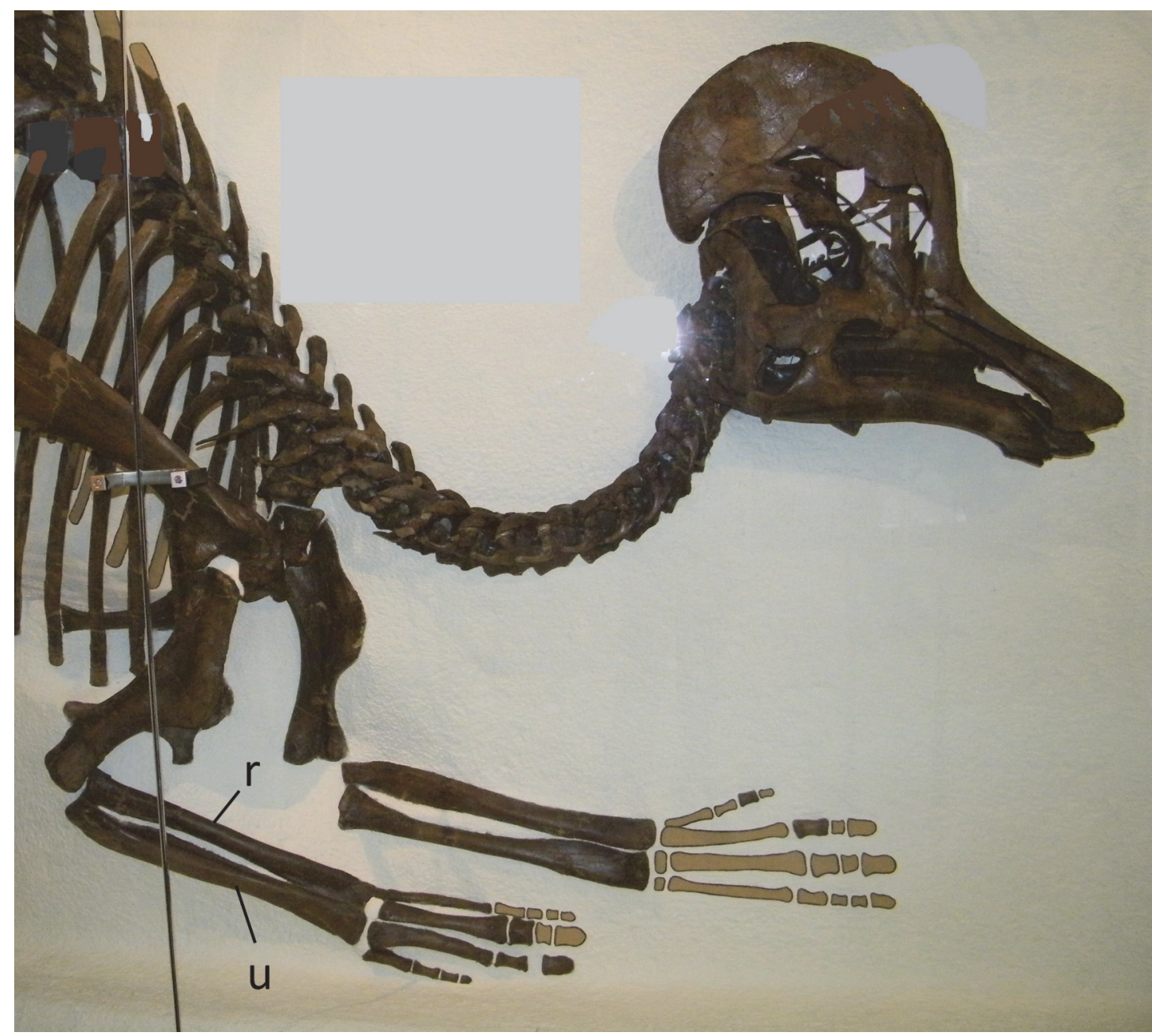

FIGURE 1. Mounted skeleton of AMNH 5338, Corythosaurus casuarius, in left lateral view. Note that in the right forelimb the radius is mounted in articulation with the lateral condyle of the humerus without distally crossing over the ulna, and that the palm faces sub-medially. Abbreviations: $\mathbf{r}$, radius; $\mathbf{u}$, ulna.

into a laterally broad, toothless bill that has inspired the nickname "duck-billed dinosaurs" (Horner et al., 2004; Creisler, 2007). A variety of cranial crests, engendered by hypertrophy of the bones bounding the nasal passages, is present in the subfamily Lambeosaurinae (Horner et al. 2004). Determination of the correct orientation of the antebrachium and hand in Hadrosauridae is of particular importance, because it has been reconstructed differently by different researchers.

Museum mounts of hadrosaurid skeletons tend to articulate the hadrosaurid forelimb in one of two configurations. In one configuration, henceforth called RL ("radius lateral") for concision, the radial head is articulated with the lateral condyle of the humerus, as in other tetrapods. The shapes of the radius and ulna are such that with the hand correctly aligned with the forearm, this configuration causes the hadrosaurid palm to face caudomedially (but more medially than caudally) (Figure 1). In the other configuration, henceforth called RM ("radius medial"), the radial head is articulated with the medial condyle of the humerus, which causes the palm to face caudally when the hand is correctly aligned with the forearm (Figure 2).

Early hadrosaurid reconstructions vacillated between the two configurations. In 1868 the Academy of Natural Sciences in Philadelphia unveiled a mounted skeleton of Hadrosaurus foulkii, the world's first dinosaurian skeletal mount (Weishampel and Young, 1996), mounted in RM (Lull and Wright, 1942, pl. 10; Weishampel and Young, 1996, Figure 4.15). In a subsequent reconstruction by Marsh (1892) of the hadrosaurid currently called Edmontosaurus annectens (Horner et al., 2004), the animal's forelimbs were illustrated in RL. In 

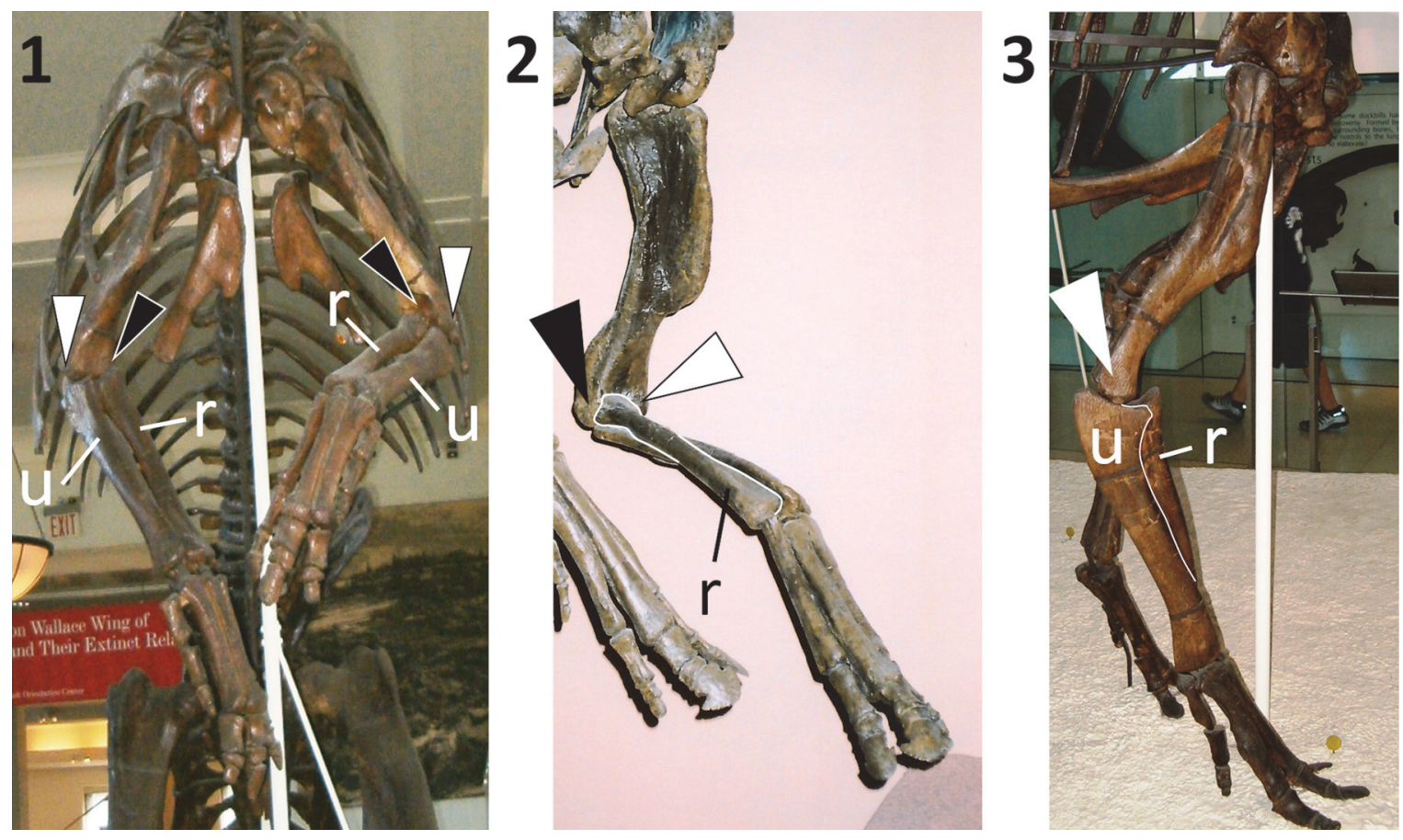

FIGURE 2. Forelimbs of hadrosaurid skeletons mounted with caudally-facing palms; black arrow indicates medial condyle of humerus, and white arrow indicates lateral condyle of humerus. 2.1. AMNH 5886, Edmontosaurus annectens, anterior view. 2.2. Cast of Edmontosaurus sp. at North American Museum of Ancient Life (Lehi, Utah), anterolateral view. 2.3. AMNH 5730, Edmontosaurus annectens, right lateral view. Note that palms face caudally in 2.1 and 2.2 due to mounting the radius in articulation with the medial condyle of the humerus, and that palms face caudally in $\mathbf{2 . 3}$ due to unnatural crossing of the distal end of the radius medially over that of the ulna.

1897 Century Magazine published the earliest fleshed-out reconstruction of a hadrosaurid with caudally-facing palms; it was a drawing by Charles Knight, for which he had sought the advice of paleontologist Edward D. Cope (Creisler, 2007). In 1901 Yale University Museum mounted a skeleton of $E$. annectens (YPM 2182) with its forelimbs in RL (Beecher, 1901). In 1904 the United States National Museum mounted a specimen of $E$. annectens (USNM 2414) with the forelimbs in RM (Lucas, 1904). Under the direction of Henry F. Osborn, Knight created a painting of a pair of $E$. annectens with caudally-facing palms in 1908 (Creisler, 2007). In the same year, the American Museum of Natural History mounted its two famous skeletons of $E$. annectens (AMNH 5730 and 5886) to match Knight's painting. To achieve caudal orientation of the palms, AMNH 5886 was mounted in RM (Figure 2.1), and AMNH 5730 was mounted in $\mathrm{RL}$ with the distal ends of the radii crossed unnaturally over the distal ends of the ulnae (Figure 2.3). Several subsequent mounts followed the example of AMNH 5886, using RM configuration to orient hadrosaurid palms caudally. Such mounts include Royal Ontario Museum mounts of Parasaurol- ophus walkeri (ROM 768) (Parks, 1922), Edmontosaurus regalis (ROM 5851) (Parks, 1935), Corythosaurus excavatus (ROM 5505) (Parks, 1935), Kritosaurus incurvimanus (ROM 764) (Lull and Wright, 1942), and Prosaurolophus maximus (ROM 787) (Lull and Wright, 1942).

While the RL condition in other tetrapods seems to rule out RM as a feasible configuration, the long history of mounting hadrosaurids in RM makes it advisable to ask whether there is reason to believe that the antebrachial configuration was modified from RL to RM in hadrosaurids. This study was conducted mainly to answer that question.

\section{Institutional Abbreviations}

AMNH: American Museum of Natural History, New York City, New York, United States. CMN, Canadian Museum of Nature, Ottawa, Ontario, Canada. JRF, Judith River Foundation, Malta, Montana, United States. ROM, Royal Ontario Museum, Toronto, Ontario, Canada. SC, Italian State Collections, Italy. YPM, Yale Peabody Museum, New Haven, Connecticut, United States. 

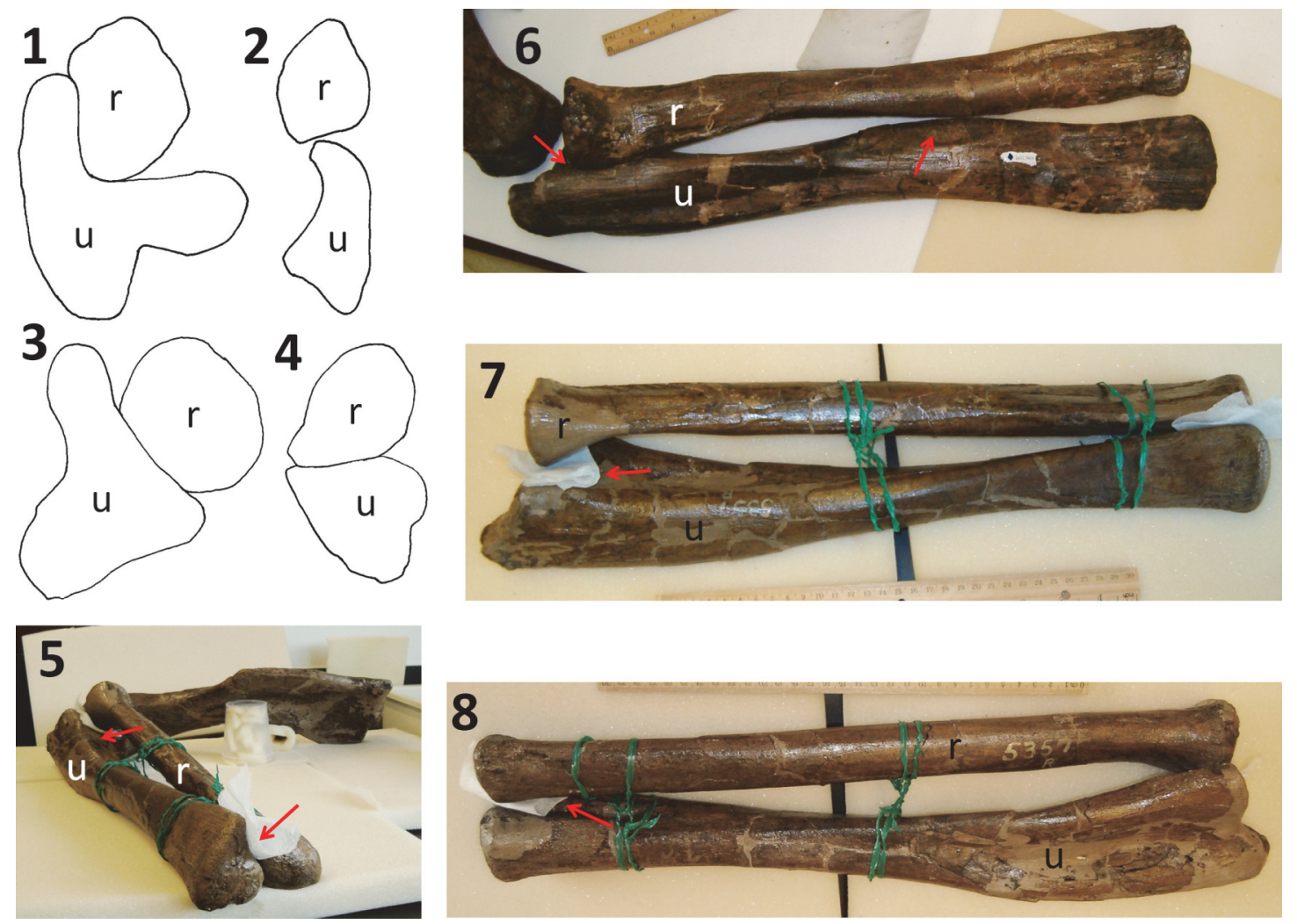

FIGURE 3. Manually rearticulated forearm bones of hadrosaurid specimens, with red arrows indicating concave surfaces on ulna that hold radius in place and thereby prevent active pronation. 3.1. CMN FV 2289 (Edmontosaurus regalis), proximal view. 3.2. CMN FV 2289, distal view 3.3. AMNH 5357 (Hypacrosaurus altispinus), proximal view. 3.4. AMNH 5357, distal view. 3.5. AMNH 5357, oblique distal view. 3.6. CMN FV 2289, lateral view, with distal end moved out of place to show concave surface on ulna. 3.7. AMNH 5357, lateral view. 3.8. AMNH 5357, medial view. Abbreviations: $r$, radius; $u$, ulna.

\section{MATERIALS AND METHODS}

Here, I have treated RL and RM reconstructions of hadrosaurid forelimbs as competing anatomical hypotheses with testable predictions. Each hypothesis makes three predictions about its respective configuration: (1) the joint surfaces of the forelimb bones allow the bones to fit together in the configuration, (2) the configuration is found in hadrosaurid specimens that were discovered with the relevant joints articulated, and (3) the configuration is compatible with ichnological evidence from hadrosaurid tracks with manus prints.

To test the first prediction I manually rearticulated the forelimb bones of two hadrosaurid specimens in which the bones had been separated for storage: CMN FV 2289 (Edmontosaurus regalis) and AMNH 5357 (Hypacrosaurus altispinus) (Figure 3).

To test the second prediction I examined an articulated specimen of Edmontosaurus annectens, AMNH (American Museum of Natural History, New York City, New York, United States) 5060 (Fig- ure 4), and an articulated specimen of E. regalis, CMN (Canadian Museum of Nature, Ottawa, Ontario, Canada) FV 8399 (Figure 5). The hands and skin of AMNH 5060 have been thoroughly described (Brown, 1912; Osborn, 1912), as have the hands of CMN FV 8399 (Lambe, 1913), but their other bones and articulations have not. AMNH 5060 , the famous dinosaur "mummy," was preserved lying on its back with much of its skin intact and with much of the skeleton-including the bones of the elbows and hands-articulated. It was mounted largely in one piece (Osborn, 1912). CMN FV 8399 was preserved lying on its side with most of its skeleton articulated. Its forelimbs are fairly well articulated (Lambe, 1913). Most of the skeleton was left in the matrix and mounted as found, but some missing manual phalanges were restored in plaster (Lambe, 1913).

To test the third prediction I consulted published literature on hadrosaur trackways. Here, the taxonomy of Edmontosaurus follows Campione and Evans (2011). 

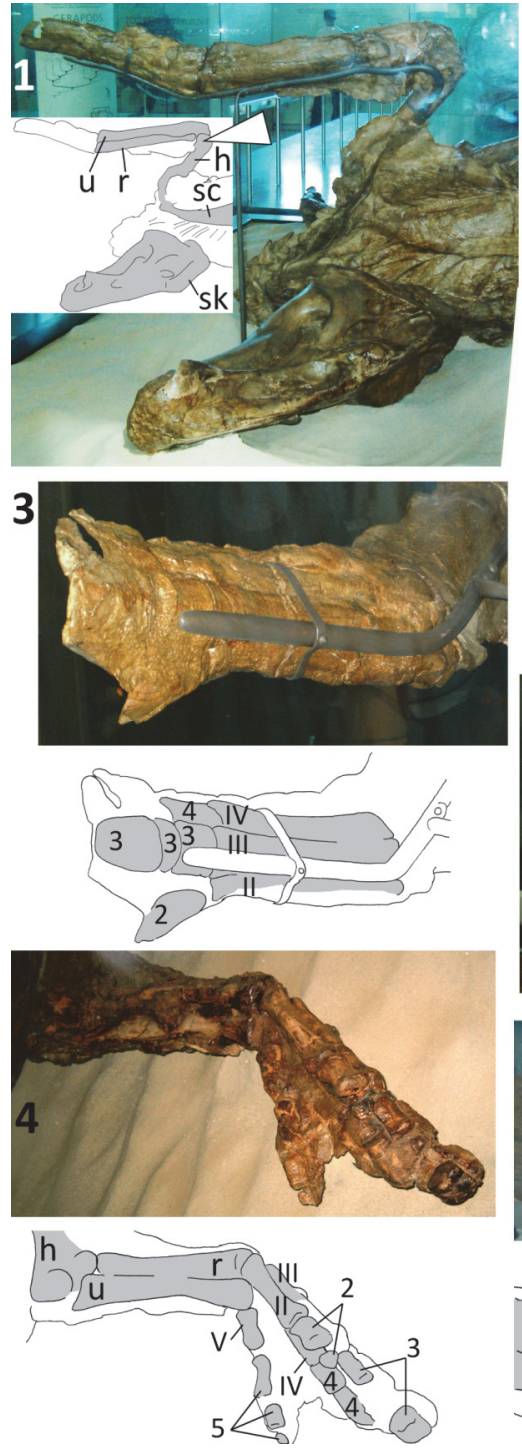
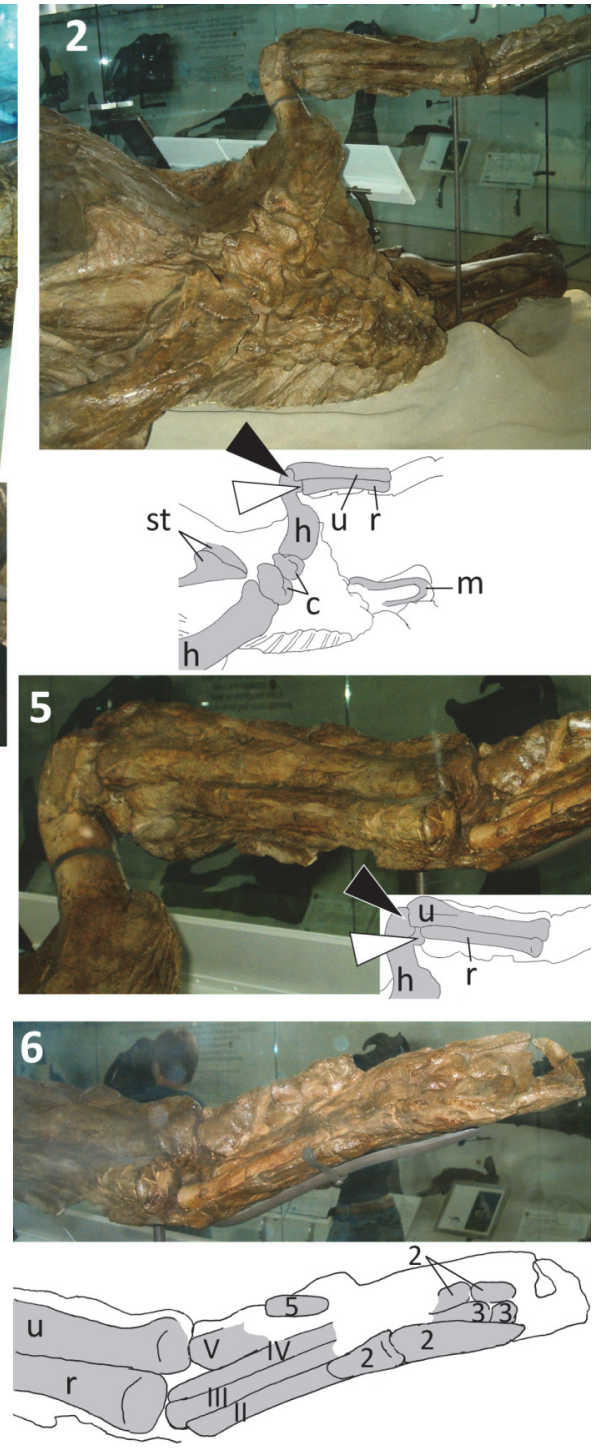

FIGURE 4. AMNH 5030, mummified Edmontosaurus annectens, showing articulations between forelimb bones; black arrow indicates medial condyle of humerus, and white arrow indicates lateral condyle of humerus. 4.1. Anterior end of specimen in dorsal view. 4.2. Anterior end of specimen in right ventral view. 4.3. Right hand in dorsal view. 4.4. Left forearm and hand in oblique (part palmar, part pollucal) view. 4.5. Right forearm in palmar view. 4.6. Right hand in palmar view. Abbreviations: c, coracoid; $\mathbf{h}$, humerus; $\mathbf{m}$, mandible; r, radius; sc, scapula; sk, skull; st, sternal plates; u, ulna. Roman numerals indicate metacarpals, and Arabic numerals indicate phalanges of the digit indicated by each numeral (e.g., all phalanges of digit II are indicated by "2").

\section{RESULTS}

When I manually rearticulated the forelimb bones of CMN FV 2289 and AMNH 5357, I found that the best fit occurs in the RL configuration. In this configuration the shapes of the bones do not allow the radius to cross over the ulna. In both specimens, concave surfaces on the ulna cradle the radius and prevent it from moving out of position (Figure $3.5-3.8$ ) Also, the proximal and distal radio-ulnar joints lack rolling surfaces (Figure 3.1 -
3.4). These data show that distal radial crossover is unnatural in hadrosaurids and that the two bones were fixed in position relative to each other, with no active pronation or supination possible.

Examination of AMNH 5060 revealed that its radius articulates with the lateral condyle of the humerus in both forelimbs, supporting the interpretation that RL is the correct configuration (Figure 4). In both forelimbs the radius is parallel to the ulna with no distal crossover. The humeral heads moved craniolaterally out of the glenoids as the 

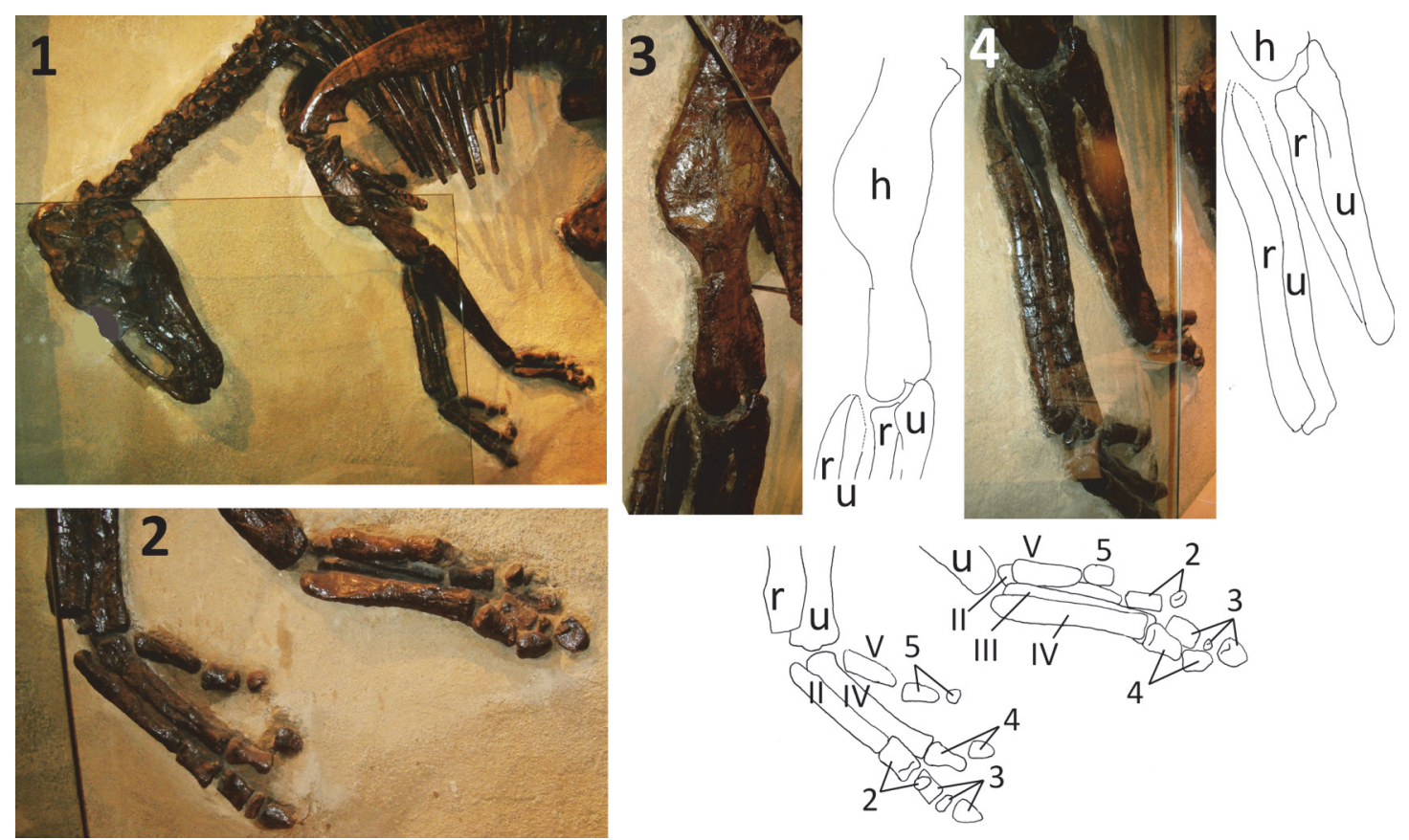

FIGURE 5. CMN FV 8399, articulated skeleton of Edmontosaurus regalis, showing articulations between forelimb bones. 5.1. Anterior end of skeleton in lateral view. 5.2. Right hand (left side of 5.2) in palmar view and left hand (right side of 5.2) in palmolateral view. 5.3. Articulations between bones of left elbow. 5.4. Articulations between bones of the right forearm (left side of 5.4) and of the left forearm (right side of 5.4). Abbreviations as in Figure 4.

corpse lay on its back, so that the shoulders became dislocated (Figure 4.2). This has created an unnatural humeral sprawl, causing the palms to face ventrally. The orientation of the elbows, wrists, and hands reveals that the palms would have faced sub-medially were the shoulders not dislocated.

In CMN FV 8399 the right elbow is not visible (Figure 5). In the left elbow the radius articulates with the lateral condyle of the humerus (Figure 5.3 ), again supporting the interpretation that $R L$ is the correct configuration. The distal ends of the radius and ulna are articulated with each other differently in the two forelimbs. The two bones lie parallel in the right forearm, so that the distal end of the radius is not crossed over that of the ulna, whereas the distal end of the radius is crossed medially all the way over that of the ulna in the left forelimb (Figure 5.4). As a result, the palms face different directions in the two forelimbs. The right palm faces sub-medially, with the fourth and fifth digits in a caudal position, while the left palm faces caudally, with the fourth and fifth digits (the latter of which is caudally displaced) in a lateral position (Figure 5.2). That the distal radial crossover in the left forelimb of this specimen is unnatural is con- firmed by the condition in its right forelimb, by the condition in both forelimbs of AMNH 5060, and by the manual rearticulations described above. It is also confirmed by the condition in articulated hadrosauroid skeletons that I did not examine but for which photographs have been published: JRF 115 (Brachylophosaurus canadensis) (Murphy et al., 2007) and SC 57021 (Tethyshadros insularis) (dalla Vecchia, 2009). In both cases the RL configuration is present, and the radial and ulnar shafts are parallel, with no distal radial crossover. The caudal orientation of the left palm of CMN FV 8399 is due to the hand's having been dragged into such an orientation as the distal end of the radius moved post-mortem into its current, unnatural position.

The RL configuration, which causes the palm to face caudomedially, agrees with hadrosaurids manus prints. Most of the plethora of known trackways attributable to hadrosaurids lack manus prints (Currie and Sarjeant, 1979; Alonso, 1980; Lockley et al., 1983; Carpenter, 1992; Lim et al., 1995; Milner et al., 2006), which suggests that hadrosaurids usually moved bipedally. In the few hadrosaurids trackways with manus prints, the palms face caudomedially (Currie et al., 1991; Lockley et al., 2001, 2006) (Figure 6). 

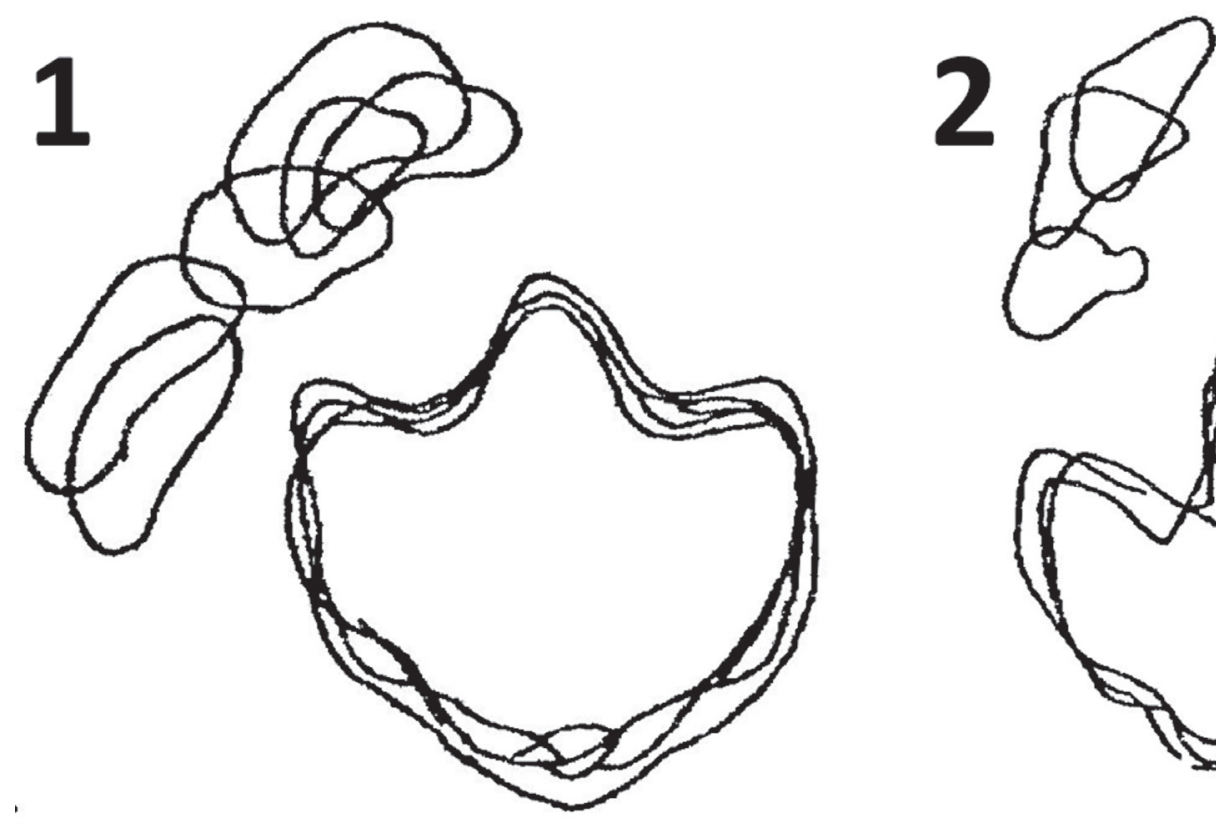

FIGURE 6. Overlay of several manus-pes pairs in hadrosaur trackways, after Lockley and Wright (2001). 6.1. Tracks from the Gething Formation (Lower Cretaceous, Canada). 6.2. Tracks from the Saint Mary River Formation (Upper Cretaceous, Canada).

\section{DISCUSSION}

A strongly medial orientation of the palms is unusual in a quadruped. In most quadrupeds the palms face caudally and the fingers flex toward the palm so as to produce a caudally-directed propulsive force during locomotion (Muybridge, 1957; Jenkins and Goslow, 1983). Anteaters (Myrmecophagidae) are exceptional in that they walk quadrupedally with palms facing medially (Orr, 2005). In anteaters the fingers curl up into the palm during locomotion so that the animal walks on its knuckles and the propulsive force is provided at the wrist, elbow, and shoulder but not the fingers (Orr, 2005). Hadrosaurids were not knuckle-walkers and therefore had to solve the problem of quadrupedal locomotion with medially-facing palms in another way. Iguanodon, a close relative of Hadrosauridae, engaged in quadrupedal locomotion with its palms facing caudomedially as in hadrosaurids (Wright, 1999). In Iguanodon the leading digit of the hand (digit II, because digit I is reduced in Iguanodon and lost in hadrosaurids) is reoriented so that it flexes caudally, toward the hind digits, rather than toward the palm (Norman, 1980), thereby producing a caudally-directed force even with sub-medially facing palms. The same may have been true of hadrosaurids, because the flexor surface of digit II faces the hind digits in AMNH 5060 (Figure 4.4, 4.6), CMN FV 8399 (Figure 5.2) and other hadro- saurid specimens found with articulated hands (Parks, 1919, 1922; Prieto-Marquez, 2007; dalla Vecchia, 2009) (Figure 7).

Manual orientation in some articulated hadrosaurid specimens appears to contradict the conclusion that the palms faced sub-medially. As found, the palms faced caudally in articulated specimens of Kritosaurus (ROM 764) and Parasaurolophus (ROM 768) (Parks, 1920, 1922). However, in both specimens this is due to postmortem rotation of the forearm bones. This is shown by the fact that in each of these specimens, as found, the olecranon process of the ulna was on the lateral side of the forelimb rather than in its natural position on the caudal side of the forelimb (Parks, 1920, 1922).

The sub-medial orientation of palm in hadrosaurids and Iguanodon was likely inherited from the common dinosaurian ancestor, because the palms plesiomorphically face medially in bipedal saurischians (Sereno, 1993; Gishlick, 2001; Carpenter, 2002; Senter and Robins, 2005; Bonnan and Senter, 2007) and in ceratopsian ornithischians (Senter, 2007; Fujiwara, 2009). In bipedal saurischians and in ceratopsians, as in hadrosaurids and Iguanodon, this is due to a lack of distal radial crossover (Sereno, 1993; Gishlick, 2001; Carpenter, 2002; Senter and Robins, 2005; Senter, 2007; Bonnan and Senter, 2007; Fujiwara, 2009). 

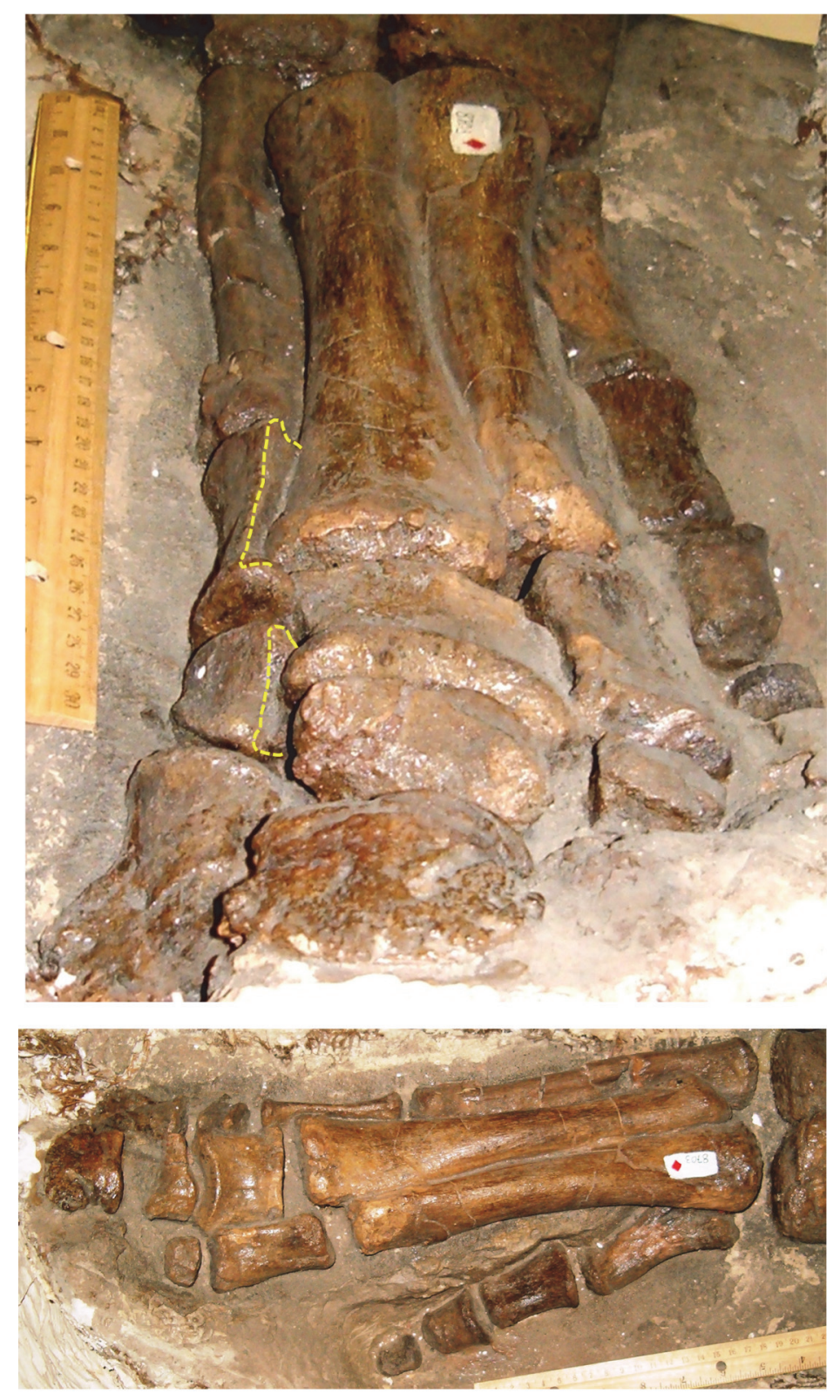

FIGURE 7. Articulated left hand of CMN FV 8703 (Lambeosaurus sp.), showing that the palmar surface (outlined with broken yellow line) of digit II faces digit III.

The practice of forcing the palms of bipedal dinosaurs to face ventrally by incorrectly mounting the radius in articulation with the medial humeral condyle is not limited to Hadrosauridae. It sometimes occurs in mounts of the bipedal sauropodomorph Plateosaurus (Mallison, 2010) and in mounted theropod skeletons (e.g., AMNH 5664: Gorgosaurus libratus; AMNH 5753: Allosaurus fragilis; personal observation, 2008). Correct articulation of the radius with the lateral condyle of the humerus is necessary for achieving the correct, sub-medial orientation of the palms in these taxa as well as Hadrosauridae.

\section{ACKNOWLEDGMENTS}

Several people deserve thanks for their help with this study, Part 11 of the Dinosaur Forelimb Project. M. Norell, C. Mehling, S. Bell, and A. Lora provided access to specimens at the American Museum of Natural History. S. Bell searched American Museum records for details of excavation and mounting of American Museum hadrosaurid skele- 
tons. K. Shepherd and M. Feuerstack provided access to specimens at the Canadian Museum of Nature. The Jurassic Foundation provided partial funding for travel to museums. Two anonymous reviewers gave helpful suggestions that improved this manuscript.

\section{REFERENCES}

Alonso, R.N. 1980. Icnitas de dinosaurios (Ornithopoda, Hadrosauridae) en el Cretacico Superior del norte de Argentina. Acta Geologica Lilloana, 15:55-63.

Beecher, C.E. 1901. The restoration of a dinosaur. Yale Scientific Monthly, 7: 291-293.

Bonnan, M.F. 2003. The evolution of manus shape in sauropod dinosaurs: implications for functional morphology, forelimb orientation, and phylogeny. Journal of Vertebrate Paleontology, 23:595-613.

Bonnan, M.F. and Senter, P. 2007. Were the basal sauropodomorph dinosaurs Plateosaurus and Massospondylus habitual quadrupeds? Special Papers in Palaeontology, 77:139-155.

Brown, B. 1912. The osteology of the manus in the family Trachodontidae. Bulletin of the American Museum of Natural History, 31:105-108.

Campione, N.E. and Evans, D.C. 2011. Cranial growth and variation in edmontosaurs (Dinosauria: Hadrosauridae): implications for latest Cretaceous megaherbivore diversity in North America. PLOS ONE, 6(9: e25186):1-12.

Carpenter, K. 1992. Behavior of hadrosaurs as interpreted from footprints in the "Mesaverde" Group (Campanian) of Colorado, Utah, and Wyoming. Contributions to Geology, University of Wyoming, 29:8196.

Carpenter, K. 2002. Forelimb biomechanics of nonavian theropod dinosaurs in predation. Senckenbergiana Lethaea, 82:59-76.

Creisler, B.S. 2007. Deciphering duckbills: a history in nomenclature, p. 185-210. In Carpenter, K. (ed.), Horns and Beaks. Ceratopsian and Ornithopod Dinosaurs. Indiana University Press, Bloomington.

Currie, P.J. and Sarjeant, W.A.S. 1979. Lower Cretaceous dinosaur footprints from the Peace River Canyon, British Columbia, Canada. Palaeogeography, Palaeoclimatology, Palaeoecology, 28:103-115.

Currie, P.J., Nadon, G.C., and Lockley, M.G. 1991. Dinosaur footprints with skin impressions from the Cretaceous of Alberta and Colorado. Canadian Journal of Earth Sciences, 28:102-115.

dalla Vecchia, F.M. 2009. Tethyshadros insularis, a new hadrosauroid dinosaur (Ornithischia) from the Upper Cretaceous of Italy. Journal of Vertebrate Paleontology, 29:1100-1116.

Fujiwara, S. 2009. A reevaluation of the manus structure in Triceratops (Ceratopsia: Ceratopsidae). Journal of Vertebrate Paleontology, 29:1136-1147.
Gishlick, A.D. 2001. The function of the manus and forelimb of Deinonychus antirrhopus and its importance for the origin of avian flight, p. 301-318. In Gauthier, J. and Gall, L.F. (eds.), New Perspectives on the Origin and Early Evolution of Birds. Yale Peabody Museum, New Haven.

Horner, J.R., Weishampel, D.B., and Forster, C.A. 2004. Hadrosauridae, p. 438-46. In Weishampel, D.B., Dodson, P., and Osmólska, H. (eds.), The Dinosauria, Second Edition. University of California Press, Berkeley.

Jenkins, F.A., Jr. and Goslow, G.E. 1983. The functional anatomy of the shoulder of the savannah monitor lizard (Varanus exanthematicus). Journal of Morphology, 175:195-216.

Lambe, L.M. 1913. The manus in a specimen of Trachodon from the Edmonton Formation of Alberta. The Ottawa Naturalist, 27:23-25.

Lim, S., Lockley, M.G., and Yang, S. 1995. First descriptions of dinosaur trackways from the Hama Formation, Cretaceous, South Korea: evidence and implications, p. 161-164. In Sun, A. and Wang, Y. (eds.), Sixth Symposium on Mesozoic Terrestrial Ecosystems and Biota, Short Papers. China Ocean Press, Beijing.

Lockley, M.G. and Wright, J.L. 2001. Trackways of large quadrupedal ornithopods from the Cretaceous: a review, p. 428-441. In Tanke, D.H. and Carpenter, K. (eds.), Mesozoic Vertebrate Life. Indiana University Press, Bloomington.

Lockley, M.G., Young, B.H., and Carpenter, K. 1983. Hadrosaur locomotion and herding behavior: evidence from footprints in the Mesaverde Formation, Grand Mesa Coal Field, Colorado. The Mountain Geologist, 20:5-14.

Lockley, M.G. Janke, P., and Theisen, L. 2001. First reports of bird and ornithopod tracks from the Lakota Formation (Early Cretaceous), Black Hills, South Dakota, p. 443-453. In Tanke, D.H. and Carpenter, K. (eds.), Mesozoic Vertebrate Life. Indiana University Press, Bloomington.

Lockley, M.G., Kukihara, R., and Mitchell, L. 2006. New dinosaur and crocodile tracksites from the Cretaceous Dakota Group of the Colorado front range, Boulder and Jefferson Counties, Colorado. New Mexico Museum of Natural History and Science Bulletin, 35:89-94.

Lucas, F.A. 1904. The dinosaur Trachodon annectens. Smithsonian Miscellaneous Collections, 45:317-320.

Lull, R.S. and Wright, N.E. 1942. Hadrosaurian dinosaurs of North America. Geological Society of America Special Papers, 40:1-242.

Mallison, H. 2010. The digital Plateosaurus II: an assessment of the range of motion of the limbs and vertebral column and of previous reconstructions using a digital skeletal mount. Palaeontologia Polonica, 55:433-458.

Marsh, O.C. 1892. Restorations of Claosaurus and Ceratosaurus. American Journal of Science, 44:343-349. 
Milner, A.R.C., Vice, G.S., Harris, J.D., and Lockley, M.G. 2006. Dinosaur tracks from the Upper Cretaceous Iron Springs Formation, Iron County, Utah. New Mexico Museum of Natural History and Science Bulletin, 35:105-113.

Murphy, N.L. 2007. "Leonardo," a mummified Brachylophosaurus (Ornithischia: Hadrosauridae) from the Judith River Formation of Montana, p. 117-133. In Carpenter, K. (ed.), Horns and Beaks. Ceratopsian and Ornithopod Dinosaurs. Indiana University Press, Bloomington.

Muybridge, E. 1957. Animals in Motion. Dover Publications, New York.

Norman, D.B. 1980. On the ornithischian dinosaur Iguanodon bernissartensis of Bernissart (Belgium). Institut Royal des Sciences Naturelles de Belgique, Mémoire, 178:1-103.

Orr, C.M. 2005. The knuckle-walking anteater: a convergence test of adaptation for purported knuckle-walking features of the African Hominidae. American Journal of Physical Anthropology, 128:639-658.

Osborn, H.F. 1912. Integument of the iguanodont dinosaur Trachodon. Memoirs of the American Museum of Natural History, 1:33-54.

Parks, W.A. 1919. Preliminary description of a new species of trachodont dinosaur of the genus Kritosaurus. Transactions of the Royal Society of Canada, Series 3, 13(4):51-59.

Parks, W.A. 1920. The osteology of the trachodont dinosaur Kritosaurus incurvimanus. University of Toronto Studies, Geological Series, 11:1-74.

Parks, W.A. 1922. Parasaurolophus walkeri, a new genus and species of crested trachodont dinosaur. University of Toronto Studies, Geological Series, 13:1-32.
Parks, W.A. 1935. New species of trachodont dinosaurs from the Cretaceous formations of Alberta with notes on other species. University of Toronto Studies, Geological Series, 37:1-45.

Prieto-Marquez, A. 2007. Postcranial osteology of the hadrosaurid dinosaur Brachylophosaurus canadensis from the Late Cretaceous of Montana, p. 91-115. In Carpenter, K. (ed.), Horns and Beaks. Ceratopsian and Ornithopod Dinosaurs. Indiana University Press, Bloomington.

Senter, P. 2006. Forelimb function in Ornitholestes hermanni Osborn (Dinosauria, Theropoda). Palaeontology, 49:1029-1034.

Senter, P. 2007. Analysis of forelimb function in basal ceratopsians (Dinosauria: Ornithischia). Journal of Zoology, 273:305-314.

Senter, P. 2010. Evidence for a sauropod-like metacarpal configuration in stegosaurian dinosaurs. Acta Palaeontologica Polonica, 55:427-432.

Senter, P. 2011. Evidence for a sauropod-like metacarpal configuration in ankylosaurian dinosaurs. Acta Palaeontologica Polonica, 56:221-224.

Senter, P. and Parrish, J.M. 2006. Forelimb function in the theropod dinosaur Carnotaurus sastrei, and its behavioral implications. PaleoBios, 26(3):7-17.

Senter, P. and Robins, J.H. 2005. Range of motion in the forelimb of the theropod dinosaur Acrocanthosaurus atokensis, and implications for predatory behaviour. Journal of Zoology, 266:307-318.

Sereno, P.C. 1993. The pectoral girdle and forelimb of the basal theropod Herrerasaurus ischigualastensis. Journal of Vertebrate Paleontology, 13:425-450.

Weishampel, D.B. and Young, L. 1996. Dinosaurs of the East Coast. Johns Hopkins University Press, Baltimore.

Wright, J.L. 1999. Ichnological evidence for use of the forelimb in iguanodontid locomotion. Special Papers in Palaeontology, 60:209-219. 